\title{
FEMORAL HERNIA
}

\author{
With some late results of the low operation \\ By M. J. BennetT-Jones, Ch.M.(L'pool), F.R.C.S.(England) \\ Surgeon, United Liverpool Hospitals; Surgeon, St. Helens Hospital \\ and S. O'Donnell, M.Ch.(N.U.I.), F.R.C.S.(England) \\ County Surgeon, Tipperary, Eire; lately Surgical Registrar, St. Helens Hospital
}

\begin{abstract}
About 20 years ago one of us was so impressed by seeing a number of direct inguinal herniae following the Lotheissen (1898) repair of a femoral hernia that he decided to try the low or Lockwood type of repair. The low operation has been used almost exclusively since that time in over 500 cases. At that time and probably at the present time the Lotheissen operation is the most popular, because it is considered to give better access to the neck of the sac, easier resection of gut should this be necessary, increased safety of a possible aberrant obturator artery if Gimbernat's ligament is divided in the presence of strangulation and finally it was considered that suture of the conjoint tendon to Cooper's ligament should produce fewer recurrences than suturing Poupart's ligament to the pectineal fascia. In spite of these apparent very weighty arguments we believe the inguinal canal should only be opened if there is an associated inguinal hernia because the transversalis fascia has to be incised in order to expose the femoral sac from the inguinal canal.
\end{abstract}

\section{Modification of the Lotheissen Operation}

The suturing of the conjoint tendon to Cooper's ligament has been facilitated by a relieving incision of the anterior rectus sheath (Tanner, 1942), while McVay (I948 and 1950) performs the same repair for inguinal and femoral hernia. The femoral canal has been closed from above by means of fascial flaps (Hughes and Fathi, I950; McFadden, 1949), a flap of external oblique (Kidd, 1948), and also by a free skin graft (Webb Jones, 1949). Nash (1948) advised a fascial strip darn.

\section{The Abdominal Approach}

Lawson Tait (1883), a great pioneer in many aspects of abdominal surgery, is credited with the first attempt to deal with a femoral hernia through the abdomen while removing an ovarian cyst. Henry (1936) popularized the approach, but it has never had a wide appeal except in bilateral cases. In strangulated cases an incision in the groin may still be necessary. The access to the neck of the sac is usually not satisfactory unless a really large mid-line incision is made. Some use a transverse incision with probably less liability to ventral herniae.

The ready acceptance of the McEvedy (1950) operation showed that surgeons were not happy with existing methods, but we have already encountered three cases, which had been operated on elsewhere, of a recurrent hernia at the outer edge of the rectus muscle: this type of hernia is more difficult to repair than a recurrent femoral hernia. The liability to a hernia at the outer edge of the rectus could almost certainly be reduced by avoiding a vertical incision in the rectus sheath. Moreover, the vertical skin incision in the groin has produced a keloid web with flexion deformity. It was the appearance of recurrent abdominal herniae after the McEvedy operation and the apparent freedom of recurrence following the low operation that suggested an investigation into the long-term results of the low operation was indicated.

\section{Technique of the Low Operation}

With a transverse skin incision at the level of the pubic spine the fatty sac is readily exposed. After isolating the sac one concentrates on exposing the neck posteriorly. It is found that there is a mass of fibrous tissue, which is the posterior layer of the pelvic fascia, around the neck of the sac, and when this has been dissected the index finger can be passed beneath the sac into the pelvis. The neck of the sac can then be brought well forward clear of Poupart's ligament. It is then obvious that the cause of strangulation is a tight ring of fibrous tissue round the neck of the sac and not Gimbernat's ligament. The latter need never be divided and so the presence 
of an abnormal obturator artery is of no interest. The division of Poupart's ligament, a procedure once advocated by Hey Groves in certain cases, is now condemned. If the hernia is strangulated it is better to insert three hernial directors and gradually stretch the neck of the sac while the assistant prevents the small intestine or omentum from falling back into the abdomen, rather than the more usual procedure of incising the neck from within with the aid of one hernial director. The latter procedure may be associated with more difficulty in closing the peritoneum later. Even if resection of gut is indicated there is usually ample exposure; if, however, the operator wants more room, a low split muscle incision should be made in the corresponding iliac fossa, an incision which never gives rise to an incisional hernia if closed without drainage. Surely the use of hot packs is as harmful to strangulated gut as the application of heat to an ischaemic foot. We think hot packs may at least aggravate postoperative ileus. Viability of gut must be judged by inspection alone after release of the strangulation. If there is any doubt about viability it is wiser to resect; this view is confirmed by an analysis of fatalities following strangulated inguinal herniae (Marsden, 1956).

The closure of the femoral canal from below is facilitated by the use of Ross's needle (1948) which enables one to place sutures through Cooper's ligament instead of the pectineal fascia.

\section{Results of the Low Operation}

According to Butters (1948) femoral herniae are four and a half times less common than inguinal herniae and this proportion is probably usual for surgical units dealing with adults, but it is amazing to read that the John Hopkins Hospital in 21 years, from 1925 to 1946 , only admitted 139 cases of femoral herniae in a total of 316,525 admissions (Koontz, I952). There is no doubt that there has been little written about the end-results of femoral herniae operations compared with the many investigations on the results of the various operations for inguinal herniae; moreover, the follow-up has usually been very short or for an unstated period of time. Wakeley (1940) operated on 6ro cases of femoral herniae between 1915 and 1939: he records 4.6 per cent. recurrences in 535 primary cases and 60.7 per cent. recurrences in 75 recurrent herniae. He definitely favoured the low operation because its recurrence rate was less than 2 per cent. (the length of the follow-up was not stated).

It was decided to try to trace cases which had been operated on at least five years ago by the low operation. We found 179 cases $(63$ females and 44 males) had been dealt with between 1939 and 1952: we confined ourselves to one hospitap so that one of us (S.O'D.) could examine all the cases. The majority were between 40 and $6 \ddot{Q}$ years of age, but there were a couple of cases i each of the first three decades as well as cases up to 80 years of age. Out of these only ro7 could. be examined as 38 had died from various uncon $\vec{F}$ nected causes; the relations of the deceased were questioned in nearly all these cases, and as far as could be ascertained the known dead had nक. further trouble with their herniae. The longe the period of follow-up, the larger will be the number of untraced patients; 34 were untraced, but the war years were notorious for this difficulty Out of the 107 cases (including 8 bilateral hernia) 4 recurrent femoral herniae were seen, one of the recurrences occurred on one side in a bilaterat case. The recurrent femoral hernia was so smat in 2 cases that the patient was unaware of it: presence and would therefore not consent to $\overrightarrow{\mathrm{d}}$ further attempt at repair. The remaining 2 case had the recurrent femoral herniae repaired rew cently, but so far they are satisfactory. Th\& incidence of inguinal herniae following the femora hernia operation revealed 6 on the same side and 5 on the opposite side. It appears that the lo operation does not predispose to inguinal herni and the 6 per cent. incidence of an inguinal hernie developing on the same side is a doubtful congrom indication of the low operation unless the Lotheissen approach can show less than 6 क्षes cent. recurrent inguinal herniae after five years Moore (1943) had 8 recurrences in 121 herniae but each recurrent case had been operated on bo the inguinal route; his total recurrence case was 6.6 per cent., but io per cent. for the Lotheisse method. Butters (1948) had 3.3 per cent. recu? rences in 120 cases using the low approach; the were no recurrences with 54 males, but 4 recur rences in 66 females. He found that the 7 pe cent. of inguinal herniae, on the same side as the femoral hernia operation, were all males. We also found that the 4 recurrent femoral herniae ad occurred in females, but we did not find that subsequent inguinal hernia on the same side was confined to males; they were in fact equal divided between the sexes.

\section{Summary and Comments}

I. The low operations appear to have a recu结 rence rate under 4 per cent. lasting over five years, but 5 to 7 per cent. develop an inguinat hernia on the same side and about the sanf proportion develop an inguinal hernia on the opposite side.

2. More figures are required concerning the late results of the modifications of the Lotheisseg 
operation, such as the Tanner slide inguinal repair.

3. An interim report on the results of the McEvedy operation should now be made.

\section{BIBLIOGRAPHY}

BUTTERS, A. G. (1948), Brit. med. F., ii, 743.

FRATKIN, L. B. (I948), Canad. med. Ass. F., 58, 365.

HAGAN, W. H., and RHOADS, J. E. (1953), Surg. Gynec. Obstet., 96, 226.

HENRY, A. K. (1936), Lancet, i, 531.

HUGHES, E. S. R., and FATHI, J. T. (1950), Ibid., i, 620.

KIDD, H. A. (1948), Brit. med. F., ii, 745.
KOONTZ, A. R. (1952), A.M.A. Arch. Surg., 64, 298. LOTHEISSEN, G. (1898), Zbl. Chir., 25, 548.

McEVEDY, P. G. (1950), Ann. roy. Coll. Surg. Engl., 7, 484.

MCFADDEN, G. D. F. (1949), Brit. med. F., ii, ro25.

McVAY, C. B. (1948), Arch. Surg., 57, 524.

McVAY, C. B., and ANSON, B. J. (1949), Surg. Gynec. Obstet., 88, 473.

MARSDEN, A. J. (1956), Personal communication.

MOORE, S. W. (1943), Surgery, 13, 145.

NASH, D. F. E. (1948), Lancet, $i, 598$.

ROSS, J. C. (r945), Brit. med. F., i, 299.

TAIT, L. (1883), Ibid., ii, 1118.

THOMPSON, W. (195I), Ibid., i, 797.

WAKELEY, C. P. G. (I940), Lancet, i, 822.

WEBB JONES, A. (1949), Brit. med. $\mathcal{F}$., i, 35 I.

\section{HOW TO GET THERE}

An Address Book for the Medical profession, showing how to reach the various Colleges, Societies, Institutes and Hospitals in or near London

New (Fourth) Edition: 1954

Price 2s. 6d. (3s. Od., post free)

Published by the

FELLOWSHIP OF POSTGRADUATE MEDICINE

60 Portland Place, London, W.I

\section{CARCINOMA OF THE BRONCHUS}

Price 3s. 11d. post free

\section{INTRODUCTORY}

Maurice Davidson, D.M., F.R.C.P.

THE INCIDENCE AND AETIOLOGY OF PRIMARY CARCINOMA OF THE LUNG

C. E. Drew, M.V.O., F.R.C.S.

\section{MEDICAL ASPECTS}

J. Anderson, M.D., F.R.C.P.

RADIOLOGICAL ASPECTS

G. Simon, M.D., D.M.R.E., F.F.R.
UNUSUAL MANIFESTATIONS

J. Smart, M.D., F.R.C.P.

CYTOLOGICAL EXAMINATION OF THE SPUTUM AND PLEURAL EFFUSION

J. L. Pinniger, D.M., M.R.C.P.

THE SCOPE OF RADIOTHERAPY

Gwen Hilton, D.M.R.E., F.F.R.

SURGERY OF CARCINOMA OF THE BRONCHUS

L. L. Bromley, M.Chir., F.R.C.S.

Published by

THE FELLOWSHIP OF POSTGRADUATE MEDICINE 60, Portland Place, London, W.1 